\title{
Theme section on mesophotic coral ecosystems: advances in knowledge and future perspectives
}

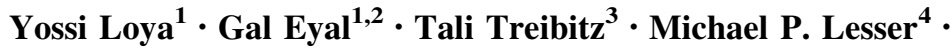 \\ Richard Appeldoorn ${ }^{5}$
}

Received: 7 December 2015/ Accepted: 22 January 2016/Published online: 8 February 2016

(C) Springer-Verlag Berlin Heidelberg 2016

\begin{abstract}
The Second International Mesophotic Coral Ecosystems (MCEs) workshop was held in Eilat, Israel, October 26-31, 2014. Here we provide an account of: (1) advances in our knowledge of MCE ecology, including the central question of the potential vertical connectivity between MCEs and shallow-water reefs (SWRs), and that of the validity of the deep-reef refugia hypothesis (DRRH); (2) the contribution of the 2014 MCE workshop to the central question presented in (1), as well as its contribution to novel MCE studies on corals, sponges, fish, and crabs; and (3) gaps, priorities, and recommendations for future research stemming from the workshop. Despite their close proximity to well-studied SWRs, and the growing evidence of their importance, our scientific knowledge of MCEs is still in its infancy. During the last five years, we have witnessed an ever-increasing scientific interest in MCEs,
\end{abstract}

Communicated by Biology Editor Howard R Lasker

Electronic supplementary material The online version of this article (doi:10.1007/s00338-016-1410-7) contains supplementary material, which is available to authorized users.

Yossi Loya

yosiloya@gmail.com

1 Department of Zoology, Tel Aviv University, Tel Aviv 69978, Israel

2 The Interuniversity Institute for Marine Sciences in Eilat, Eilat 88103, Israel

3 The Leon H. Charney School of Marine Science, University of Haifa, Haifa 3498838, Israel

4 School of Marine Science and Ocean Engineering, University of New Hampshire, Durham, NH 03824, USA

5 Department of Marine Sciences, University of Puerto Rico, Mayagüez 00681-9000, Puerto Rico expressed in the exponential increase in the number of publications studying this unique environment. The emerging consensus is that lower MCE benthic assemblages represent unique communities, either of separate species or genetically distinct individuals within species, and any significant support for the DRRH will be limited to upper MCEs. Determining the health and stability of MCEs, their biodiversity, and the degree of genetic connectivity among SWRs and MCEs, will ultimately indicate the ability of MCEs to contribute to the resilience of SWRs and help to guide future management and conservation strategies. MCEs deserve therefore management consideration in their own right. With the technological advancements taking place in recent years that facilitate access to MCEs, the prospects for exciting and innovative discoveries resulting from MCE research, spanning a wide variety of fields, are immense.

Keywords Mesophotic coral ecosystem - Deep-reef refugia hypothesis - Connectivity - Biodiversity · Community structure $\cdot$ Coral-reef management

\section{Introduction}

The Second International Mesophotic Coral Ecosystems (MCEs) workshop was held at the Interuniversity Institute for Marine Sciences in Eilat (IUI), Israel, October 26-31, 2014. It followed the first MCE workshop, held in Jupiter, Florida, in 2008 (Hinderstein et al. 2010). The major goals of the 2014 workshop in Eilat were to assess how the field has changed since the 2008 workshop, exchange findings among peers and students, encourage new international collaborations, and identify gaps and priorities for future MCE research. The workshop covered a variety of research areas, 
including biology, ecology, and physiological properties of mesophotic species, conservation and management, connectivity (i.e., the exchange of genes/individuals among marine populations) between MCEs and shallow-water reefs (SWRs), biodiversity of mesophotic reefs, geology, and
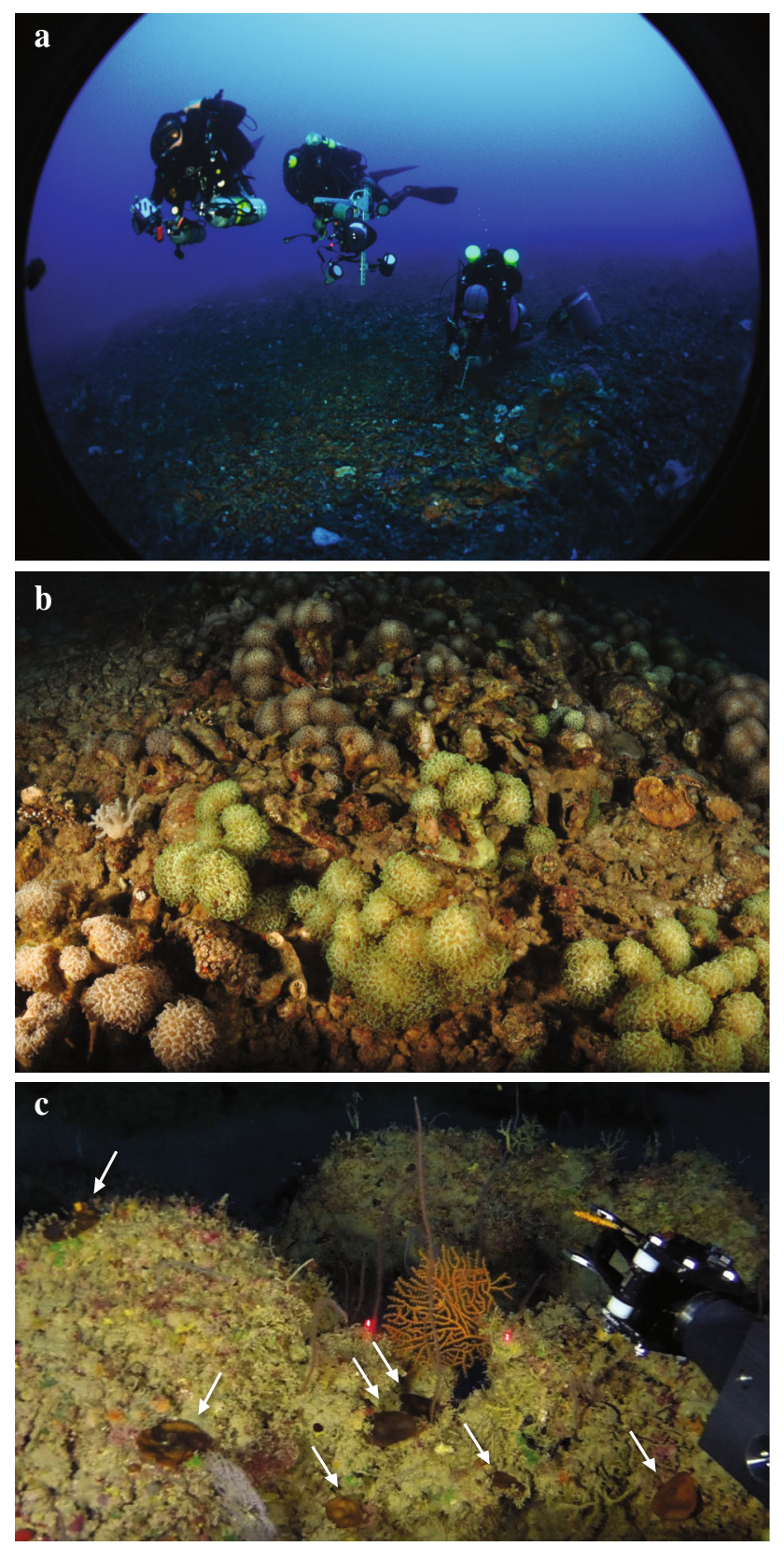

Fig. 1 MCE research projects conducted during the 2014 workshop at Eilat, Red Sea. a Rebreather divers sampling corals at $60 \mathrm{~m}$ depth (photograph: Elliott Jessup). b Euphyllia paradivisa, one of the most abundant scleractinian coral species at the MCEs of the Gulf of Eilat/ Aqaba (36-72 m depth). c Abundant gorgonian and anthipatharian colonies and a population of Leptoseris fragilis (indicated by white arrows), the most abundant scleractinian coral in the lower MCEs of Eilat (80-146 m depth) sampled by ROV during the workshop. The distance between the two red laser dots in the middle of the photograph is $10 \mathrm{~cm}$ innovations in underwater research technologies (Fig. 1). For details on the workshop, see www.mceisrael.com.

\section{Mesophotic coral ecosystems}

Reef corals have been experiencing increasing stress due to local anthropogenic perturbations and global climate change, resulting in damage to coral reproduction and recruitment failure (e.g., Hoegh-Guldberg et al. 2007; Baird et al. 2009; Harrison 2011; Pandolfi et al. 2011; Jackson et al. 2014). Globally, about $19 \%$ of coral reefs have already been lost, with a further $35 \%$ expected to be lost in the next $40 \mathrm{yr}$ (Wilkinson 2008). In view of the global degradation of SWRs, coral-reef scientists and managers are showing an increasing interest in MCEs (see recent comprehensive review by Kahng et al. 2014).

MCEs are characterized by the presence of light-dependent corals and associated communities, typically found at depths ranging from approximately $30-40 \mathrm{~m}$ to $150 \mathrm{~m}$ in tropical and subtropical regions (Lesser et al. 2009; Hinderstein et al. 2010; Kahng et al. 2010). One of the most important abiotic factors on coral reefs, and specifically in MCEs, is the irradiance of photosynthetically active radiation (PAR; 400-700 nm). Typically, the depth at which PAR is reduced to $1 \%$ of surface irradiance (the photic depth; Ryther 1956) defines the bottom of the euphotic zone (Clarke 1936), but corals and other photoautotrophs still occur below this point (see Lesser et al. 2009 for discussion). There is now broad agreement that the mesophotic zone is subdivided into the 'upper mesophotic' and 'lower mesophotic,' with a transition at approximately $60 \mathrm{~m}$, depending on water clarity and depth of the thermocline (Bongaerts et al. 2010, 2015a; Slattery et al. 2011).

\section{Vertical connectivity and the deep-reef refugia hypothesis}

In many localities MCEs are linked physically, and possibly also biologically, to their shallow-water counterparts. MCEs, therefore, have the potential to be refugia for shallow coral-reef taxa, and a source of propagules (i.e., vertical connectivity), contributing to the resilience of SWRs (e.g., Hughes and Tanner 2000; Lesser et al. 2009; Bongaerts et al. 2010; Kahng et al. 2014; Holstein et al. 2016a). Glynn (1996) was the first to note that deep reefs are less affected by thermal stress events and could be potential refuges. Hughes and Tanner (2000) first suggested that deeper reefs potentially provide a spatial refuge for coral species with wide depth distributions and could serve as a source of larvae for seeding recovery in SWRs. A further development of the concept was provided by 
Lesser et al. (2009), who discussed vertical connectivity in a broader context and were the first to suggest the implications of potential refugia for reef management. Based on their work on Caribbean coral reefs, Bongaerts et al. (2010) unified various references and coined the term 'deep-reef refugia hypothesis' and its acronym (DRRH). Questions addressing the potential for genetic/demographic connectivity between MCEs and SWRs, and the validity of the DRRH, comprise central research objectives of many recent MCE studies.

The DRRH suggests that deep reefs are more stable than shallow reefs (Bongaerts et al. 2010) or environmentally more predictable [sensu Loya (1972), i.e., the amplitude of changes of abiotic and biotic parameters is smaller in MCEs than in SWRs]. Accordingly, MCEs should be less vulnerable and potentially more resistant to disturbances that reduce the quality of suitable habitats for shallowwater benthic communities (e.g., storms, temperature increases, and associated bleaching or diseases, pollution, sedimentation and turbidity, habitat fragmentation, eutrophication, and associated algal blooms; Riegl and Piller 2003; West and Salm 2003; Smith et al. 2008; Lesser et al. 2009; Kahng et al. 2014). MCEs may thus serve as a source of propagules for SWRs, facilitating the repopulation and return to pre-disturbance conditions of SWRs (e.g., Hughes and Tanner 2000; Lesser et al. 2009; Bongaerts et al. 2010). However, the available data on the human impacts and ecological stability of MCEs remain sparse, and long-term datasets and experimental studies on MCEs below $40 \mathrm{~m}$ depth are virtually nonexistent.

\section{Recent advances in knowledge and highlights of new findings in this theme section}

The reports presented in this Coral Reefs theme section provide insight into the advances of our scientific understanding and the potential management needs of MCEs. In the following sections, we introduce those studies and discuss them in the context of the research that has been reported since the comprehensive review by Kahng et al. (2014).

\section{Vertical connectivity and the DRRH}

The questions of vertical connectivity between MCEs and SWRs and the validity of the DRRH constitute central questions approached by six of the studies included in the theme section. Assessments of vertical connectivity between MCEs and SWRs and their implications for management must address a number of factors. The first is the type of organisms being considered. Fishes, which have substantial swimming capabilities, could potentially show a greater degree of connectivity over a broader depth range compared to corals and other benthic species. In their review, Kahng et al. (2014) made the point that few data exist on vertical connectivity patterns of mobile reef organisms. Since then, there has been a significant increase in the number of studies (Fig. 2; Electronic Supplementary Material, ESM, Table S1), especially on fish populations that have demonstrated significant species overlap between MCEs and SWRs and an absence of genetic differentiation with depth.

One of the main contributions in this theme section has been an increased knowledge on the ecology of mesophotic fish assemblages. Rosa et al. (2016) conducted the first quantitative characterization of reef fish assemblages (30-90 m depth) of the small and remote St. Peter and St. Paul's Archipelago (mid-Atlantic ridge, Brazil), while Pinheiro et al. (2016) used underwater visual assessments to characterize MCE fish assemblages ranging from 45 to $130 \mathrm{~m}$ depth in Bermuda and Curaçao; Bermuda had lower fish richness and abundance but higher biomass than Curaçao. Both studies found distinct vertical zonation in the fish assemblages and concluded that depth seems to be an important driver of community structure. For example, Rosa et al. (2016) identified distinct fish assemblages occurring at $30-50 \mathrm{~m}$ and at $50-90 \mathrm{~m}$, with the upper mesophotic assemblage containing species that also occur on SWRs ( $80 \%$ of all species), while the deeper assemblage contained endemic and mesophotic specialists. Both studies also found that the composition of the benthic communities strongly influenced differences in fish assemblages. Lindfield et al. (2016) used baited cameras to examine the distribution of fishery-targeted reef fish in the

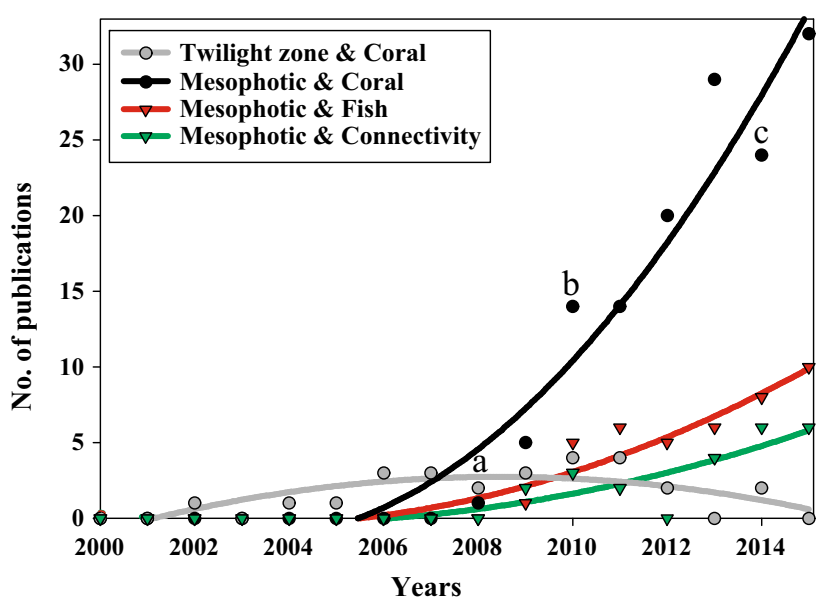

Fig. 2 Number of publications on mesophotic coral ecosystems (MCEs) 2000-2015. a The first MCE workshop in 2008, b the MCE theme section in Coral Reefs in 2010, c the 2014 MCE workshop. Source: Web of Science search results for the keywords indicated in the box November 2015 
southern Mariana Islands and found that the majority of targeted species had vertical distributions that ranged from shallow depths $(10 \mathrm{~m})$ to depths of at least $70 \mathrm{~m}$. In contrast to most studies, they showed that the abundance and biomass of fishery-targeted reef fish species actually increased with depth (to $60 \mathrm{~m}$ ), with distributions below this depth limited by available habitat.

These results parallel those of Bejarano (2013) and Bejarano et al. (2014) in Puerto Rico, who found that while most species in MCEs (30-70 m depth) were common inhabitants of SWRs, some were restricted to mesophotic depths, and overall depth was important in determining assemblage structure. Additionally, well-developed mesophotic reefs had a higher number of species and individuals than less rugose areas. Importantly, many species, particularly the larger, fishery-targeted species, used shallowwater nursery habitats followed by ontogenetic migration to mesophotic depths, and many of these species showed increasing abundance and biomass with depth. Larger predators may show an even higher degree of connectivity and dependence between MCEs and SWRs.

Direct tracking studies of movement or measures of genetic continuity over depth also provide strong evidence for connectivity. Papastamatiou et al. (2015) used acoustic telemetry and stable isotope analyses to investigate the diel and seasonal movements of Galapagos sharks captured from 50 to $70 \mathrm{~m}$ depth at an uninhabited Pacific atoll. They concluded that MCEs may provide some prey to upperlevel predators but also serve as a refuge habitat. Furthermore, the frequent movements between habitats suggest that marine predators may transport a significant amount of nutrients across depths, particularly from SWRs to MCEs. Tenggardjaja et al. (2014), who studied genetic connectivity in the damselfish, Chromis verater, between shallow (30 m) and mesophotic (30-150 m) depths at Johnston Atoll, found no significant genetic differentiation by depth and similarly concluded there were high levels of vertical connectivity.

The emerging consensus is that for reef fishes: (1) MCEs serve as a valuable habitat; (2) species turnover increases with depth; yet (3) there is considerable connectivity between the upper MCEs and SWRs; and (4) for some species, particularly those of commercial importance, this connectivity is critical and can extend into lower MCEs. All these conclusions point to support of the DRRH, especially for species subject to intense fishing pressure, and emphasize the importance of linking management of SWRs and MCEs.

Studies on mesophotic taxa of limited vagility are rare, and the study of Hurley et al. (2016) on the species assemblages of brachyuran crabs from 12 to $90 \mathrm{~m}$ in Hawaii helps to fill an important gap in evaluating connectivity and the DRRH. Using specimens obtained from 2-yr deployments of collectors, they found the greatest separation among assemblages between 12 and $30 \mathrm{~m}$, with the latter most closely related to the assemblage at $60 \mathrm{~m}$. Sixty-one percent of observed species occurred at $12 \mathrm{~m}$, and $40 \%$ occurred only at this depth. $<5 \%$ of the species were found across all depths. While this suggests that there is some connectivity between SWRs and the upper MCEs (i.e., between 30 and $60 \mathrm{~m}$ ), this does not extend significantly to either shallower $(13 \mathrm{~m})$ or deeper $(90 \mathrm{~m})$ depths. Hurley et al. (2016) further suggest that the 30-60-m assemblages represent either a transition between SWRs and lower MCEs or a unique intermediate assemblage.

For corals, the distinction between upper and lower mesophotic zones already suggests that vertical connectivity with SWRs is limited to $60 \mathrm{~m}$ depth. Additional studies using genetic approaches have now addressed whether such divisions occur also within species [e.g., Pochon et al. (2015) for dominant coral genus Leptoseris in Hawaii; Brazeau et al. (2013) for Montastraea cavernosa; Bongaerts et al. (2015b) for Agaricia grahamae and A. undata in the Caribbean; and Costantini et al. (2011) for the precious red coral, Corallium rubrum, in the Mediterranean]. Emerging consensus is that lower MCE benthic assemblages represent unique communities, either of separate species or genetically distinct individuals within species, and any significant support for the DRRH will be limited to shallow MCEs. Both conclusions argue that MCEs deserve management consideration in their own right for biodiversity conservation and to protect their roles as critical habitat and as a source of valuable resources.

In their contribution to this theme section, Costantini and Abbiati (2016) investigated genetic variability of C. rubrum between 55 and $120 \mathrm{~m}$ depth in the Mediterranean, along $\sim 1500 \mathrm{~km}$ of coastline. Population structure was analyzed using nine microsatellite loci and the putative control region of the mtDNA. Significant differences occurred at the large scale, suggesting, for example, little exchange between the Ligurian Sea-Tuscan Archipelago and the Tyrrhenian-Ionian Seas along the west coast of Italy. However, a reduced gene flow was also found within areas with scales above $10 \mathrm{~km}$, particularly within the Tuscan Archipelago. They concluded that the patchy distribution of suitable habitats coupled with complex hydrodynamic regimes, rather than habitat variability among sampling sites, most influenced population genetic structure. This supports the previous studies of $C$. rubrum by Cannas et al. (2015) showing isolation by distance at a scale of $<10 \mathrm{~km}$, indicating that $C$. rubrum populations are sustained largely by local recruitment and that mesophotic populations could not effectively seed recovering shallower banks.

In the end, whether mesophotic reefs will serve as refuge areas depends on a variety of factors such as water currents, available habitat for settlement, coral fecundity, fertilization rates, larval survivorship and behavior, pelagic 
larval duration, vertical exchange of larvae between habitats, habitat/depth selection, and post-settlement survivorship (Hughes and Tanner 2000; Munday et al. 2009; Holstein et al. 2015). To gain insight into this question, Holstein et al. (2016a) employed a biophysical model, the first of its kind, to simulate the exchange of larvae between MCEs and SWRs in the US Virgin Islands (USVI). Two generalist coral species with different reproductive life histories, the broadcast spawning Orbicella faveolata and the brooding Porites astreoides, were modeled among habitats and across a 0- to 50-m-depth gradient. They showed that demographic subsidy from mesophotic to shallow areas appears likely for both species based on local oceanography, reproductive characteristics, and larval traits tested over a wide range of depth-sensitive factors, such as fertilization rates and post-settlement survivorship.

Previous genetic studies in the Caribbean basin and elsewhere found vertical connectivity in Montastraea cavernasa, a broadcast spawner (Brazeau et al. 2013; Serrano et al. 2014). However, Serrano et al. (2014) observed genetic differentiation by depth $(<10,15-20$ and $\geq 25 \mathrm{~m}$ ) in Florida, but not in Bermuda or the USVI. However, sampling only extended significantly into mesophotic depths in Bermuda. Brazeau et al. (2013) collected $M$. cavernosa at shallow (3-10 m), medium $(15-25 \mathrm{~m})$, deep $(30-50 \mathrm{~m})$ and very deep $(60-90 \mathrm{~m})$ depths and found significant genetic differentiation between shallow/medium depths and very deep depths at both Little Cayman Island and the Bahamas, indicative of low vertical population connectivity. Both Serrano et al. (2014) and Brazeau et al. (2013) invoked selection and asymmetric vertical connectivity from shallow to deeper reefs suggesting that mesophotic reefs may actually be receiving larval subsidies from SWRs. A similar spatial heterogeneity in vertical structure was reported for Seriatopora hystrix, a brooding coral, between northwest and northeast Australia (van Oppen et al. 2011).

Nevertheless, this does not rule out support for the DRRH over the short term, as corals can be long-lived, such that existing mesophotic colonies would have ample opportunity, even at low rates, to reseed SWRs in case of catastrophic loss. Indeed, Holstein et al. (2016a) suggest that although the direct subsidy of larvae from MCEs to SWRs may be low, multigenerational recruitment events spanning the depth gradient between MCEs and SWRs may allow for generalist brooding corals to disperse vertically throughout their range. These studies also support the assertion that local oceanography and population dynamics must be evaluated if we wish to obtain a broader understanding of the potential roles of MCEs in coral-reef metapopulations, and that the validity of the DRRH may be site-specific. In all studies addressing the DRRH, it is critical that the depth range being assessed be explicitly reported, as there is no biological significance to the upper depth boundary of MCEs, and studies extending marginally beyond $30 \mathrm{~m}$ depth may not be indicative of processes throughout the MCE depth range, or even within the upper mesophotic zone.

\section{Processes structuring MCEs}

While research on MCEs has been gaining impressive momentum (Fig. 2; ESM Table S1), the recommendation in Lesser et al. (2009) still holds true-Long-term monitoring and experimental studies of the abiotic and biotic attributes of MCEs are essential for understanding the processes structuring these currently understudied systems' - and should continue to be a primary focus of future reef studies as, due to their degradation, SWRs and the ecosystem services they provide continue to be threatened. In this context, the study by Eyal et al. (2016) presents a needed perspective. They used both long- and short-term in situ and ex situ experiments to explore the physiological plasticity and competitive abilities of the endangered scleractinian coral species Euphyllia paradivisa (NOAA 2014) in order to explain its depth distribution (36-72 m depth) and dominance (73\% of the total coral cover) in the Gulf of Eilat/Aqaba, Red Sea (Fig. 1b). The study thus examined important factors including the species' response to variable light intensities, heterotrophic capabilities, competitive abilities, and the possibility of finding a deepreef refuge from fish predation.

The potential for a deep-reef refuge from predation was also studied by Slattery et al. (2016). Sponges are one of the dominant components of lower MCE communities, particularly in the western Atlantic (Lesser et al. 2009), and some species are distributed along the entire shallow to mesophotic depth gradient, making them ideal test subjects for investigating the role of chemical defense against predators. Slattery et al. (2016) present the first chemical ecology studies from MCEs (10-76 m depth) of the Bahamas and Cayman Islands. They show that Plakortis angulospiculatus, a common Caribbean sponge, growed faster and invested more energy in protein synthesis at mesophotic depths than conspecifics at SWR, where more investment was spent on chemical defense against spongivores.

MCEs are potentially great reservoirs of coral diversity and fecundity, yet there is a striking gap in our knowledge of the reproductive traits of their coral communities and their potential to influence patterns of coral-reef persistence (Holstein et al. 2015, 2016a, b; Eyal-Shaham et al. 2016). Almost all our knowledge on coral reproduction originates from research conducted on SWRs (the reproductive traits of $\sim 450$ coral species are known today), while our knowledge of the reproductive traits of corals in MCEs is minute, with fewer than ten species studied to date. In their 
contribution to this theme section, Prasetia et al. (2016) studied the sexual reproductive biology of Acropora tenella in upper MCEs (40 m depth) at Okinawa, Japan, and concluded that overall, gametogenesis was similar to that of other Acropora species in SWRs, but the fecundity of this species (8-9 number of eggs per polyp) and its gonad index $\left(\sim 100\right.$ eggs per $\left.\mathrm{cm}^{2}\right)$ was lower than that of most acroporids. They suggested that the reproductive biology of corals in upper MCEs may be similar to that of their congeners in SWRs. Eyal-Shaham et al. (2016) report for the first time on the reproductive patterns, abundance, living cover, and survivorship under different light treatments of two scleractinian species found exclusively within MCEs of Eilat, Israel, Red Sea at $60 \mathrm{~m}$ depth, Alveopora allingi and A. ocellata. Both species were high in both abundance and relative cover and had a gonad index (mean monthly fecundity prior to spawning) of $\sim 48$ and 23 oocytes per $\mathrm{cm}^{2}$, respectively. Populations of the brooding coral Stylophora pistillata in the Red Sea had lower fecundity at deeper sites $(25-45 \mathrm{~m})$ than at shallow sites $(5 \mathrm{~m})$, but values varied considerably between successive years in the shallow-water populations (Rinkevich and Loya 1987). In the USVI, Holstein et al. (2015) investigated the reproductive performance of the threatened coral O. faveolata over the extent of its vertical range $(0-50 \mathrm{~m})$ to assess mesophotic contributions to regional larval pools. Over equal habitat areas, mesophotic coral populations were found to produce over one order of magnitude more eggs than nearby shallow populations. Positive changes with depth in both population abundance and polyp fecundity contributed to this discrepancy. In a subsequent study, Holstein et al. (2016b) investigated the relationship between depth and fecundity in the brooding coral, $P$. astreoides from 5 to $37 \mathrm{~m}$ in the USVI. Despite a trend of increasing planula production with depth, no significant differences were found in mean peak planula density between shallow, mid-depth, and mesophotic sites. The authors suggest that mesophotic ecosystems are reproductive refuges for $P$. astreoides in the USVI, and may behave as refugia for its metapopulations providing that vertical larval exchanges are viable.

Currently, due to the paucity of our knowledge of reproductive traits of scleractinian corals in MCEs compared with SWRs, it is premature to draw any unifying conclusions about patterns in their reproductive strategies. Understanding how reproductive performance changes across environmental gradients is central to the study of evolutionary ecology and to the successful management of natural populations and threatened species. As shallow habitats further degrade due to climate change and local habitat degradation, the relative contributions of deeper living corals to the larval pool will likely increase (Holstein et al. 2015, 2016a, b).

\section{Conservation and management of MCEs}

Earlier assessments assumed that because of their depth and remote locations MCEs were subject to fewer and less severe anthropogenic and natural threats. While still potentially true, recent studies now show that such immunity cannot be assumed. Land-based sources of sedimentation/turbidity, eutrophication, and pollution all threaten MCEs. Appeldoorn et al. (2016) compared adverse anthropogenic impacts on MCE benthic and fish communities off the south coast of Puerto Rico and discuss management implications. The exploratory work was conducted through a series of remotely operated vehicle (ROV) dives (72 and $111 \mathrm{~m}$ depth) and diver-based phototransects (50-70 m depth). Given the importance of anthropogenic impacts, especially on reef areas close to shore, they advocate that the management considerations given to risk assessment for SWRs should be extended to MCEs when evaluating potential impacts.

Using a ROV, Etnoyer et al. (2016) recorded the decline in condition of sea fans (Octocorallia, Alcyonacea) on lower MCEs (60-90 m depth) in the northern Gulf of Mexico before and after the Deepwater Horizon oil spill. They present clear evidence of direct injury and decline in the health of sea fans at sites situated below the surface slick. The time frame suggests that the oil spill was the likely causative agent of the decline.

Overfishing is perhaps the most widespread but least studied potential stress to MCEs, as documentation involves the assessment of both fish and benthic communities and an understanding of the trophic connections between the two (Bejarano 2013; Lindfield et al. 2016). That MCEs provide an important habitat for targeted reef fish and are thus areas important for sustainable fishery management, again warrants that MCEs be given management consideration equal to that for SWRs.

The series of studies on the precious red coral, $C$. rubrum (Costantini et al. 2011; Cannas et al. 2015; Costantini and Abbiati 2016) all suggest that there has been a significant impact of exploitation, even at the population genetic level, and that the recolonization potential for extirpated patches may be limited.

To date, ignorance regarding the importance and extent of MCEs has resulted in their low management priority among many governments, nongovernmental organizations, and local communities. Thus, despite new data documenting both their importance and vulnerability, they are still not well protected (e.g., Bridge et al. 2013). An encouraging exception is the Israeli Government's response to new evidence of extensive MCEs in the Red Sea and the establishment in 2009 of the Coral Sea Reserve in Eilat (Gulf of Aqaba, Red Sea), which extends the existing Coral Beach Nature Reserve to $500 \mathrm{~m}$ off shore to $50 \mathrm{~m}$ depth (NPA 2009). 


\section{Gaps, priorities, and recommendations for future research on MCEs}

Not all MCEs are the same, and the definition using depth distributions, while useful as a starting point, does not embrace other environmental parameters or indicator species as other possible metrics (Bongaerts et al. 2010, 2015a; Slattery et al. 2011). The role of various abiotic factors, such as light, temperature, dissolved organic and inorganic nutrients, sedimentation, current flow, and geomorphology, thought to be important in regulating MCE structure and function, is still poorly understood. There is a basic need to further document community assemblages and dynamics to understand the critical processes that structure MCEs over multiple spatial and temporal scales (Eyal et al. 2016). Vertical and horizontal connectivity has been identified as an important driver of productivity and diversity, and defining the extent of connectivity within MCEs and between shallower and deeper ecosystems is needed if the larger ecological function of MCEs, including their stability (Bongaerts et al. 2010), environmental predictability (sensu Loya 1972), resilience (sensu Hughes et al. 2003, 2010), and role as refugia is to be more fully understood. Quantifying functional connectivity will require studies on reproduction, settlement and recruitment, and ontogenetic migrations to inform modeling (Holstein et al. 2016a), and to supplement inferences derived from genetic patterns. The ecophysiology of mesophotic organisms underlies the larger development of MCEs and how they function (e.g., Lesser et al. 2009; Slattery et al. 2016). It is especially important to understand how individual organisms respond to low light conditions (e.g., ecological plasticity vs adaptation; Eyal et al. 2016), particularly with respect to energetic inputs (e.g., photosynthesis, exogenous nutrient sources; Crandall et al. 2016), and the role of microbial ecology as related to nutrient recycling, symbiosis, the holobiont community, and organismal health. Substantial advancements in these areas, coupled with ecological modeling (e.g., Holstein et al. 2016a) grounded in empirical data and the inclusion of oceanographic processes, promise the most significant progress in our state of knowledge on MCEs.

Studies of anthropogenic impacts within MCEs are still under-represented because of the paucity of studies, the inherent bias to study well-developed, healthy MCEs, and the difficulty and expense in working at these depths (Appeldoorn et al. 2016). The primary threats to MCEs are the same as to SWRs (overfishing, water quality degradation, habitat destruction, invasive species, disease, climate change). While the absolute magnitude of these threats may be lower within MCEs, the relative magnitude may be similar, especially for light-dependent organisms, already under the energetic limitations that underlie productivity and resilience.

The increased use of technical diving to access MCEs, especially closed-circuit rebreathers, has greatly facilitated and expanded MCE research (e.g., Sherman et al. 2013; Jessup 2014). However, the cost and training of MCE researchers in general still limit their numbers. Short-term improvements could be obtained through the sharing of information and resources, including technology improvements, space available on research cruises, and training opportunities. Additionally, recent funding trends de-emphasizing man-in-the-sea approaches may hinder research in MCEs if diving activities are affected, because divers can potentially conduct more science, more efficiently. Therefore, more emphasis on technology development is needed for MCEs, with the stress on bringing technology to science (ESM Table S2).

\section{Conclusions}

Despite their close proximity to well-studied SWRs, and the growing evidence of their importance, our scientific knowledge of MCEs is still in its infancy. Basic information on the taxonomic composition, depth range, habitat preferences, abundance, and distribution of MCE taxa is scarce. The processes structuring MCE communities are even less understood, leading to a critical gap in the knowledge necessary for developing future management and conservation policies. The extent, diversity, and function of MCEs argue for the implementation of direct management action. MCEs and their associated resources should be incorporated into regulatory frameworks, environmental impact statements related to coastal development, fishery regulations, and the design of marine protected areas. Increased management and public awareness is critical. Management priorities include increased mapping and monitoring activities and the incorporation of this knowledge into maritime domain awareness programs. With the technological advancements taking place in recent years that facilitate access to MCEs, the prospects for exciting and innovative discoveries resulting from MCE research, spanning a wide variety of fields, are immense. Although the papers in this special theme section only touch on the scope of current work addressing various aspects of MCE biology and ecology, we hope that we have continued to evoke interdisciplinary scientific and community interest in MCEs and to promote increased collaboration among countries, institutions, agencies, and individuals to advance our knowledge, conservation, and management of MCEs. 
Acknowledgments The Second International Mesophotic Coral Ecosystems (MCEs) workshop would not have been possible without the generous seed support of an anonymous organization. We are also most grateful to the support obtained from the Israeli Ministry of Environmental Protection and Israel Nature and Park Authority, and especially from the Underwater Observatory Marine Park at Eilat. We are much indebted to the Interuniversity Institute for Marine Sciences in Eilat (IUI) for hosting the workshop and greatly contributing to its success. Special thanks are due to P. Bongaerts, T. Bridge, S. Kahng, S.A. Sandin, and three anonymous reviewers for their constructive comments on an earlier version of the manuscript.

\section{References}

Appeldoorn R, Ballantine D, Bejarano I, Carlo M, Nemeth M, Otero E, Pagan F, Ruiz H, Schizas N, Sherman C, Weil E (2016) Mesophotic coral ecosystems under anthropogenic stress: a case study at Ponce, Puerto Rico. Coral Reefs 35

Baird AH, Guest JR, Willis BL (2009) Systematic and biogeographical patterns in the reproductive biology of scleractinian corals. Annu Rev Ecol Evol Syst 40:551-571

Bejarano I (2013) Deep reef fishes off La Parguera insular slope, Puerto Rico, and their connectivity with shallow reefs. Ph.D. Thesis, University of Puerto Rico, Mayagüez

Bejarano I, Appeldoorn RS, Nemeth M (2014) Fishes associated with mesophotic coral ecosystems in La Parguera, Puerto Rico. Coral Reefs 33:313-328

Bongaerts P, Ridgway T, Sampayo EM, Hoegh-Guldberg O (2010) Assessing the 'deep reef refugia hypothesis': focus on Caribbean reefs. Coral Reefs 29:309-327

Bongaerts P, Carmichael M, Hay KB, Tonk L, Frade PR, HoeghGuldberg O (2015a) Prevalent endosymbiont zonation shapes the depth distributions of scleractinian coral species. R Soc Open Sci 2:140297

Bongaerts P, Frade PR, Hay KB, Englebert N, Latijnhouwers KRW, Bak RPM, Vermeij MJ, Hoegh-Guldberg O (2015b) Deep down on a Caribbean reef: lower mesophotic depths harbor a specialized coral-endosymbiont community. Sci Rep 5:7652

Brazeau DA, Lesser MP, Slattery M (2013) Genetic structure in the coral Montastraea cavernosa: assessing genetic differentiation among and within mesophotic reefs. PLoS One 8:e65845

Bridge TC, Hughes TP, Guinotte JM, Bongaerts P (2013) Call to protect all coral reefs. Nat Clim Chang 3:528-530

Cannas R, Sacco F, Cau A, Coluccia E, Cristina M, Angelo F (2015) New insights into connectivity patterns of mesophotic red coral (Corallium rubrum) populations. Hydrobiologia 759:63-73

Clarke GL (1936) Light penetration in the Western North Atlantic and its application to biological problems. Rapp P V Reun Cons Int Explor Mer 101:3-14

Costantini F, Abbiati M (2016) Into the depth of population genetics: pattern of structuring in mesophotic red coral populations. Coral Reefs 35

Costantini F, Rossi S, Pintus E, Cerrano C, Gili J-M, Abbiati M (2011) Low connectivity and declining genetic variability along a depth gradient in Corallium rubrum populations. Coral Reefs 30:991-1003

Crandall JB, Teece MA, Estes BA, Manfrinob C, Ciesla JH (2016) Nutrient acquisition strategies in mesophotic hard corals using compound specific stable isotope analysis of sterols. J Exp Mar Bio Ecol 474:133-141

Etnoyer JP, Wickes LN, Silva M, Dubick JD, Balthis L, Salgado E, MacDonald IR (2016) Decline in condition of gorgonian octocorals on mesophotic reefs in the northern Gulf of Mexico: before and after the Deepwater Horizon oil spill. Coral Reefs 35
Eyal G, Eyal-Shaham L, Cohen I, Tamir R, Ben-Zvi O, Sinniger F, Loya Y (2016) Euphyllia paradivisa, a successful mesophotic coral in the northern Gulf of Eilat/Aqaba, Red Sea. Coral Reefs 35

Eyal-Shaham L, Eyal G, Tamir R, Loya Y (2016) Reproduction, abundance and survivorship of two Alveopora spp. in the mesophotic reefs of Eilat, Red Sea. Sci Rep 6:20964

Glynn PW (1996) Coral reef bleaching: facts, hypotheses and implications. Glob Chang Biol 2:495-509

Harrison PL (2011) Sexual reproduction of scleractinian corals. In: Dubinsky Z, Stambler N (eds) Coral reefs: an ecosystem in transition. Springer, Netherlands, pp 59-85

Hinderstein LM, Marr JCA, Martinez FA, Dowgiallo MJ, Puglise KA, Pyle RL, Zawada DG, Appeldoorn R (2010) Theme section on "Mesophotic coral ecosystems: characterization, ecology, and management". Coral Reefs 29:247-251

Hoegh-Guldberg O, Mumby PJ, Hooten AJ, Steneck RS, Greenfield P, Gomez E, Harvell CD, Sale PF, Edwards AJ, Caldeira K (2007) Coral reefs under rapid climate change and ocean acidification. Science 318:1737-1742

Holstein DM, Smith TB, Gyory J, Paris CB (2015) Fertile fathoms: deep reproductive refugia for threatened shallow corals. Sci Rep 5:12407

Holstein D, Paris CB, Vaz AC, Smith TB (2016a) Modeling vertical coral connectivity and mesophotic refugia. Coral Reefs 35

Holstein DM, Smith TB, Paris CB (2016b) Depth-independent reproduction in the reef Coral Porites astreoides from shallow to mesophotic zones. PLoS One 11:e0146068

Hughes TP, Tanner JE (2000) Recruitment failure, life histories, and long-term decline of Caribbean corals. Ecology 81:2250-2263

Hughes TP, Baird AH, Bellwood DR, Card M, Connolly SR, Folke C, Grosberg R, Hoegh-Guldberg O, Jackson JBC, Kleypas J, Lough JM, Marshall P, Nystrom M, Palumbi SR, Pandolfi JM, Rosen B, Roughgarden J (2003) Climate change, human impacts, and the resilience of coral reefs. Science 301:929-933

Hughes TP, Graham NAJ, Jackson JBC, Mumby PJ, Steneck RS (2010) Rising to the challenge of sustaining coral reef resilience. Trends Ecol Evol 25:633-642

Hurley KK, Timmers MA, Godwin LS, Copus JM, Skillings DJ, Toonen RJ (2016) An assessment of shallow and mesophotic reef brachyuran crab assemblages on the south shore of $\mathrm{O}^{\prime} \mathrm{ahu}$, Hawai' ${ }^{\prime}$ i. Coral Reefs 35

Jackson JBC, Donovan MK, Cramer KL, Lam W (2014) Status and trends of Caribbean coral reefs: 1970-2012. Global Coral Reef Monitoring Network, IUCN, Gland, Switzerland

Jessup ME (2014) Mesophotic coral ecosystems: tools and techniques for scientific exploration. In: Eckert G, Keller S, Tamone S (eds) Diving for Science 2014. Proceedings Am Acad Underwat Sci 33rd Symp, pp 7-14

Kahng S, Copus J, Wagner D (2014) Recent advances in the ecology of mesophotic coral ecosystems (MCEs). Curr Opin Environ Sustain 7:72-81

Kahng SE, Garcia-Sais JR, Spalding HL, Brokovich E, Wagner D, Weil E, Hinderstein LM, Toonen RJ (2010) Community ecology of mesophotic coral reef ecosystems. Coral Reefs 29:255-275

Lesser MP, Slattery M, Leichter JJ (2009) Ecology of mesophotic coral reefs. J Exp Mar Bio Ecol 375:1-8

Lindfield SJ, Harvey ES, Halford AR, McIlwain JL (2016) Mesophotic depths as refuge areas for fishery-targeted species on coral reefs. Coral Reefs 35

Loya Y (1972) Community structure and species diversity of hermatypic corals at Eilat, Red Sea. Mar Biol 13:100-123

Munday PL, Leis JM, Lough JM, Paris CB, Kingsford MJ, Berumen ML, Lambrechts J (2009) Climate change and coral reef connectivity. Coral Reefs 28:379-395 
NOAA (2014) NOAA lists 20 new corals as threatened under the Endangered Species Act. www.fisheries.noaa.gov/stories/2014/ 08/corals_listing.html

NPA (2009) New marine reserve in Israel to include mesophotic reef http://go.nature.com/k16BCK

Pandolfi JM, Connolly SR, Marshall DJ, Cohen AL (2011) Projecting coral reef futures under global warming and ocean acidification. Science 333:418-422

Papastamatiou YP, Meyer CG, Kosaki RK, Wallsgrove NJ, Popp BN (2015) Movements and foraging of predators associated with mesophotic coral reefs and their potential for linking ecological habitats. Mar Ecol Prog Ser 521:155-170

Pinheiro HT, Goodbody-Gringley, Jessup ME, Shepherd B, Chequer AD, Rocha LA (2016) Upper and lower mesophotic coral reef fish communities evaluated by underwater visual censuses in two Caribbean locations. Coral Reefs 35

Pochon X, Spalding HL, Padilla-Gamino JL, Gates RD (2015) Depth specialization in mesophotic corals (Leptoseris spp.) and associated algal symbionts in Hawai'i. R Soc Open Sci 2:140351

Prasetia R, Sinniger F, Harii S (2016) Gametogenesis and fecundity of Acropora tenella (Brook 1892) in a mesophotic coral ecosystem in Okinawa, Japan. Coral Reefs 35

Riegl B, Piller WE (2003) Possible refugia for reefs in times of environmental stress. Int J Earth Sci 92:520-531

Rinkevich B, Loya Y (1987) Variability in the pattern of sexual reproduction of the coral Stylophora pistillata at Eilat, Red Sea: a long-term study. Biol Bull 173:335-344

Rosa MR, Alves AC, Medeiros DV, Coni EOC, Ferreira CM, Ferreira BP, Rosa R, Souza R, Amado-Filho GH, de Moura RL, Thompson FL, Sumida PYG, Francini-Filho RB (2016) Mesophotic reef fish assemblages of the remote St. Peter and St. Paul's Archipelago, Mid-Atlantic Ridge, Brazil. Coral Reefs 35

Ryther JH (1956) Photosynthesis in the ocean as a function of light intensity. Limnol Oceanogr 1:61-70

Serrano X, Baums IB, O'Reilly K, Smith TB, Jones RJ, Shearer TL, Nunes FLD, Baker AC (2014) Geographic differences in vertical connectivity in the Caribbean coral Montastraea cavernosa despite high levels of horizontal connectivity at shallow depths. Mol Ecol 23:4226-4240

Sherman C, Appeldoorn R, Ballantine D, Bejarano I, Carlo M, Kesling D, Nemeth M, Pagan F, Ruiz H, Schizas N, Weil E (2013) Exploring the mesophotic zone: diving operations and scientific highlights of three research cruises across Puerto Rico and US Virgin Islands. In: Lang MA, Sayer MDJ (eds) Proceedings of the 2013 AAUS/ESDP Curaçao joint international scientific diving symposium, October 24-27, 2013, Curaçao. American Academy of Underwater Sciences, Dauphin Island, AL, pp 297-312

Slattery M, Lesser MP, Brazeau D, Stokes MD, Leichter JJ (2011) Connectivity and stability of mesophotic coral reefs. J Exp Mar Bio Ecol 408:32-41

Slattery M, Gochfeld DJ, Diaz MC, Thacker RW, Lesser MP (2016) Variability in chemical defense across a shallow to mesophotic depth gradient in the Caribbean sponge Plakortis angulospiculatus. Coral Reefs 35

Smith TB, Nemeth RS, Blondeau J, Calnan JM, Kadison E, Herzlieb S (2008) Assessing coral reef health across onshore to offshore stress gradients in the US Virgin Islands. Mar Pollut Bull 56:1983-1991

Tenggardjaja K, Bowen B, Bernardi G (2014) Vertical and horizontal genetic connectivity in Chromis verater, an endemic damselfish found on shallow and mesophotic reefs in the Hawaiian Archipelago and adjacent Johnston Atoll. PLoS One 9:e115493

van Oppen MJH, Bongaerts P, Underwood JN, Peplow LM, Cooper TF (2011) The role of deep reefs in shallow reef recovery: an assessment of vertical connectivity in a brooding coral from west and east Australia. Mol Ecol 20:1647-1660

West JM, Salm RV (2003) Resistance and resilience to coral bleaching: implications for coral reef conservation and management. Conserv Biol 17:956-967

Wilkinson C (2008) Status of coral reefs of the world: 2008. Global Coral Reef Monitoring Network and Reef and Rainforest Research Centre, Townsville, Australia 